\title{
Assessment of naturally occurring radionuclides around England and Wales: Application of the G-BASE dataset to estimate doses to non-human species
}

\author{
D.G. Jones ${ }^{1}$, J.D. Appleton ${ }^{1}$, N. Breward ${ }^{1}$, A.C. Mackenzie ${ }^{1}$, C. Scheib1, \\ N.A. Beresford ${ }^{2}$, C.L. Barnett ${ }^{2}$, M.D. Wood $^{3}$ and D. Copplestone ${ }^{4}$ \\ ${ }^{1}$ British Geological Survey (BGS), Kingsley Dunham Centre, Keyworth, Nottingham \\ NG12 5GG, UK \\ ${ }^{2}$ Centre for Ecology \& Hydrology, CEH-Lancaster, Lancaster Environment Centre, \\ Library Avenue, Bailrigg, Lancaster LA1 4AP, UK \\ ${ }^{3}$ Radioecology Unit, SWIMMER, University of Liverpool, The Nicholson Building, \\ Liverpool L69 3GP, UK \\ ${ }^{4}$ Environment Agency, PO Box 12, Richard Fairclough House, Knutsford Road, \\ Warrington WA4 1HG, UK
}

\begin{abstract}
An assessment of the natural radiation dose to wildlife in England and Wales was made to determine the contribution it may make to the total radiation dose estimated during environmental impact assessments. Significant use was made of systematic datasets for environmental media (stream sediments, stream waters and soils), in particular those produced by the Geochemical Baseline Survey of the Environment (G-BASE) project. This provided extensive, although variable, coverage for different elements and sample types after normalisation of data to account for changes in sampling and analysis over time. Almost complete coverage for K in stream sediments was achieved by merging G-BASE and Wolfson Atlas data. This required normalisation of the Wolfson data to the G-BASE results. Coverage was improved greatly for $\mathrm{U}$ and $\mathrm{Th}$ in sediments, and $\mathrm{K}, \mathrm{U}$ and $\mathrm{Th}$ in soils, by using the strong relationship between soils and sediments and geology (both solid and superficial) to extrapolate the data. The total $\mathrm{U}$, Th and $\mathrm{K}$ data were used to derive activity concentrations of ${ }^{238} \mathrm{U}$ and ${ }^{232} \mathrm{Th}$ series radionuclides and ${ }^{40} \mathrm{~K}$. External dose rates to wildlife were then estimated from derived media concentrations; internal dose rates were estimated from measured activities in biota or activities predicted using recommended concentration ratios.
\end{abstract}

\section{INTRODUCTION}

A method for impact assessment of ionising radiation on wildlife is being used by the Environment Agency to undertake assessments of Natura 2000 sites in England and Wales [1, 2]. However, the contribution that naturally occurring radionuclides make to the radiation dose received by non-human species needs to be determined to compliment the impact assessment methodology.

This paper describes work conducted to assess the background radiation dose rates to non-human biota in terrestrial and freshwater ecosystems in England and Wales concentrating on the derivation of media activity concentration databases. Estimates of activity concentrations of ${ }^{40} \mathrm{~K},{ }^{238} \mathrm{U}$ and ${ }^{232} \mathrm{Th}$ series radionuclides in environmental media (soil, stream sediments and stream waters) have been made from total K, $\mathrm{U}$ and Th concentrations derived mainly from the ongoing Geochemical Baseline Survey of the Environment (G-BASE), conducted in the United Kingdom by the British Geological Survey (BGS).

\section{METHODS}

For over 35 years BGS have been conducting a geochemical survey of the UK under the G-BASE project and its precursors [3, 4]. This includes determinations of $\mathrm{K}, \mathrm{U}$ and Th concentrations in soils, stream sediments and stream waters. The G-BASE sampling procedures are detailed in Johnson et al. [4]. Samples are collected at an optimum density of one every $1.5-2 \mathrm{~km}^{2}$ for stream 
sediments and waters and $2 \mathrm{~km}^{2}$ for soils. The extent of available data is illustrated for $\mathrm{K}$ in Figure 1; coverage for $\mathrm{K}$ is similar to that for $\mathrm{U}$ and slightly better than that for $\mathrm{Th}$ (the total number of samples which have been analysed is: K-28694, U-33627, Th-24567).

As the G-BASE survey has been ongoing for many years there have been changes in both analytical procedures and sampling. Both these issues have required normalisation of the data for the purposes of this work. This process is fully described in Beresford et al. [5]. It includes levelling between different analytical techniques and sample types, for example surface and subsurface soils.

The geochemical survey data are currently incomplete across the UK and coverage is different for each sample type. Almost complete coverage was obtained for K in stream sediments (Figure 1) by combining the BGS data with that of the Wolfson Atlas [6]. Normalisation between the BGS and Wolfson data was achieved through linear quantile transformation for areas covered by both surveys (Figure 2). For $\mathrm{U}$ and $\mathrm{Th}$ in sediments and $\mathrm{K}, \mathrm{U}$ and $\mathrm{Th}$ in soils, a more complete coverage (Figure 3) was achieved by geological extrapolation (i.e. using relationships between soils/sediments and bedrock/superficial geology).
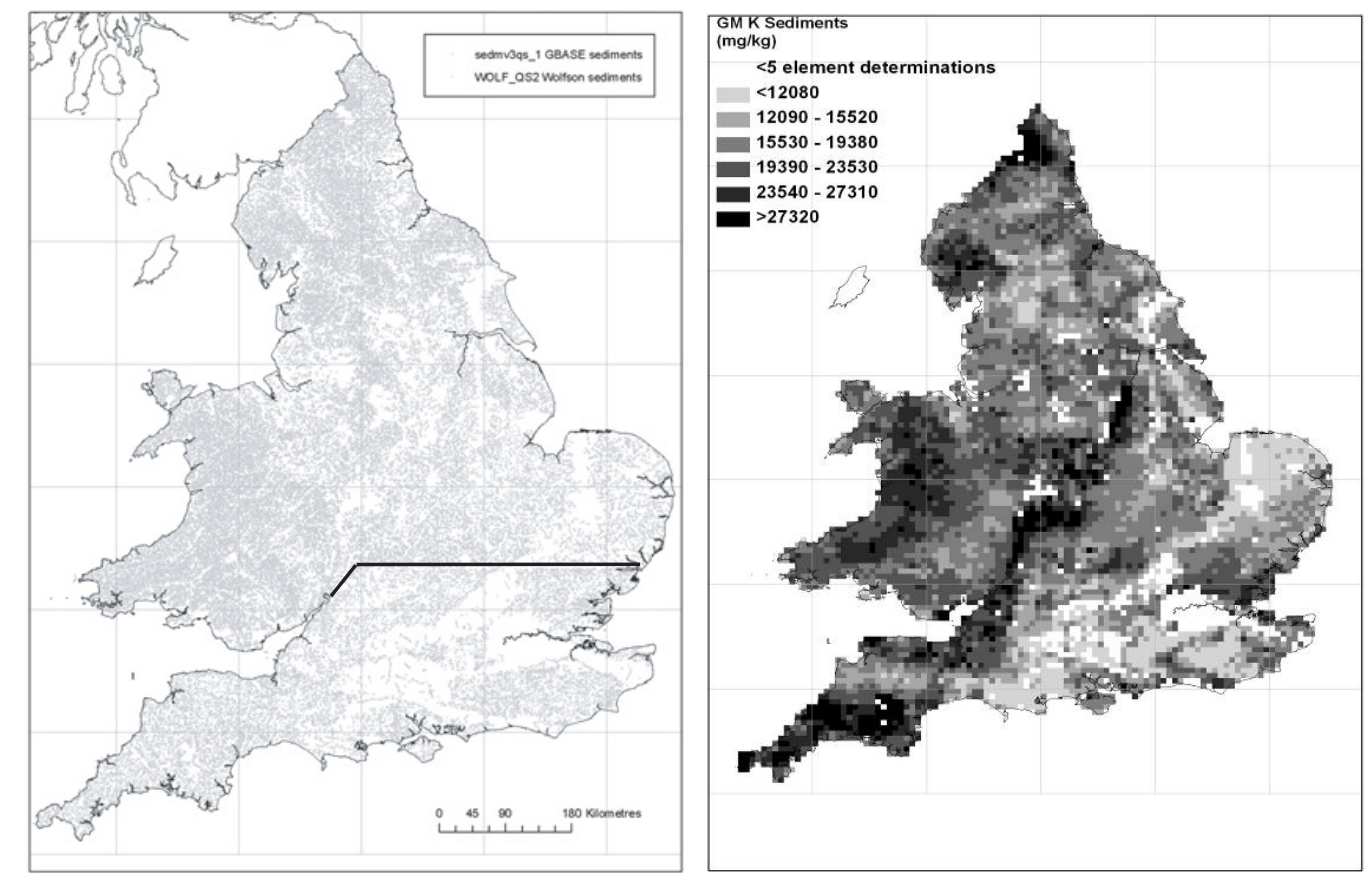

Figure 1. Left: Sample coverage for $\mathrm{K}$ in stream sediments with G-BASE samples to the north of the line and Wolfson Atlas samples used to the south. Right: Geometric mean $(\mathrm{GM})(5 \times 5 \mathrm{~km})$ for $\mathrm{K}$ for stream sediments based on combined BGS and Wolfson Atlas data.

Simplified bedrock and superficial geology codes based on BGS 1: 50000 scale digital geological maps [7] were attributed to each soil sample location. Geometric means for each element were calculated for each $1 \mathrm{~km}$ grid square and parent material (bedrock plus superficial geology) polygon from the nearest 5 soil sample values for that parent material. These data were then used to compute geometric means for each $25 \mathrm{~km}^{2}(5 \times 5 \mathrm{~km})$ grid square using area-weighted geometric mean $(\mathrm{GM})$ values for each parent material found in the square (Figure 1 presents data on this basis). This involved summing the products of the mean element content for each $1 \mathrm{~km}$ grid square/parent material polygon (derived from the 5 nearest data points on that parent material) and the area of that polygon and dividing the sum 


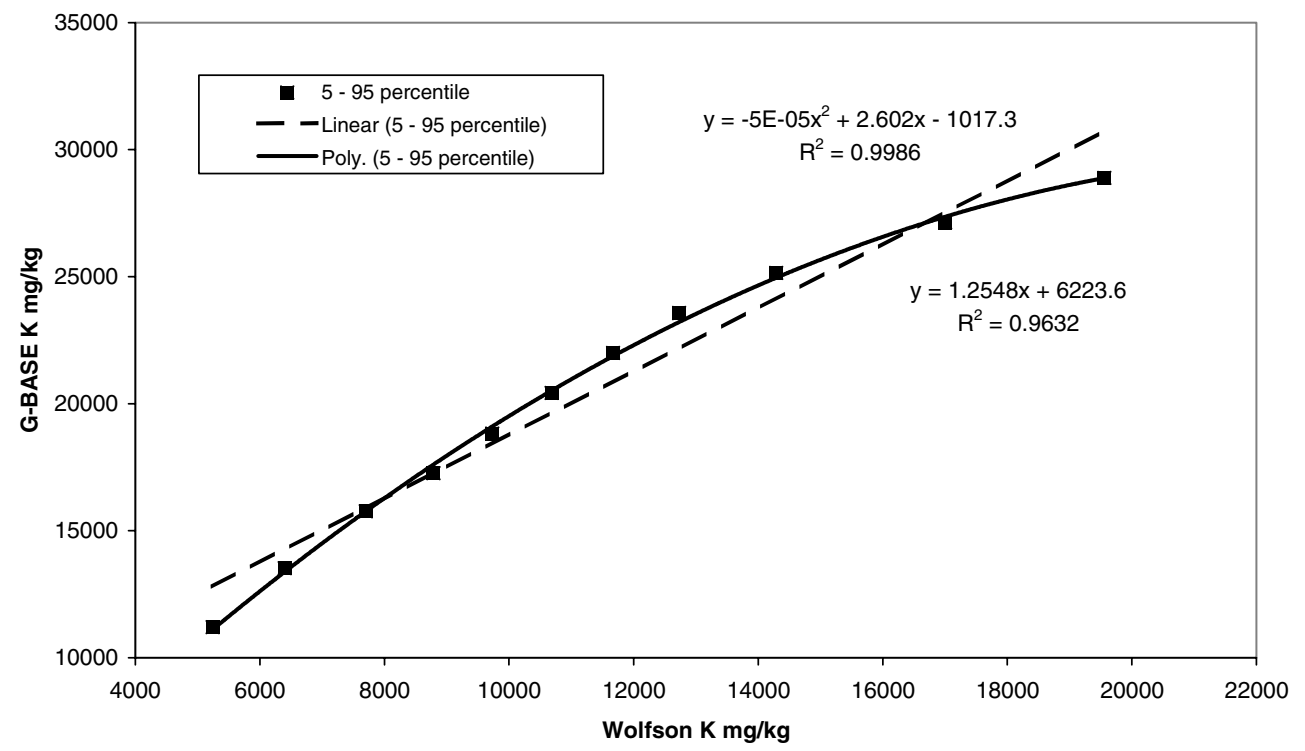

Figure 2. Linear quantile transformation of Wolfson $\mathrm{K}$ in stream sediment to GBASE XRF equivalent $\mathrm{K}$ in stream sediments (5-95 percentile range; data from this study). The polynomial fit was used for the data transformation.
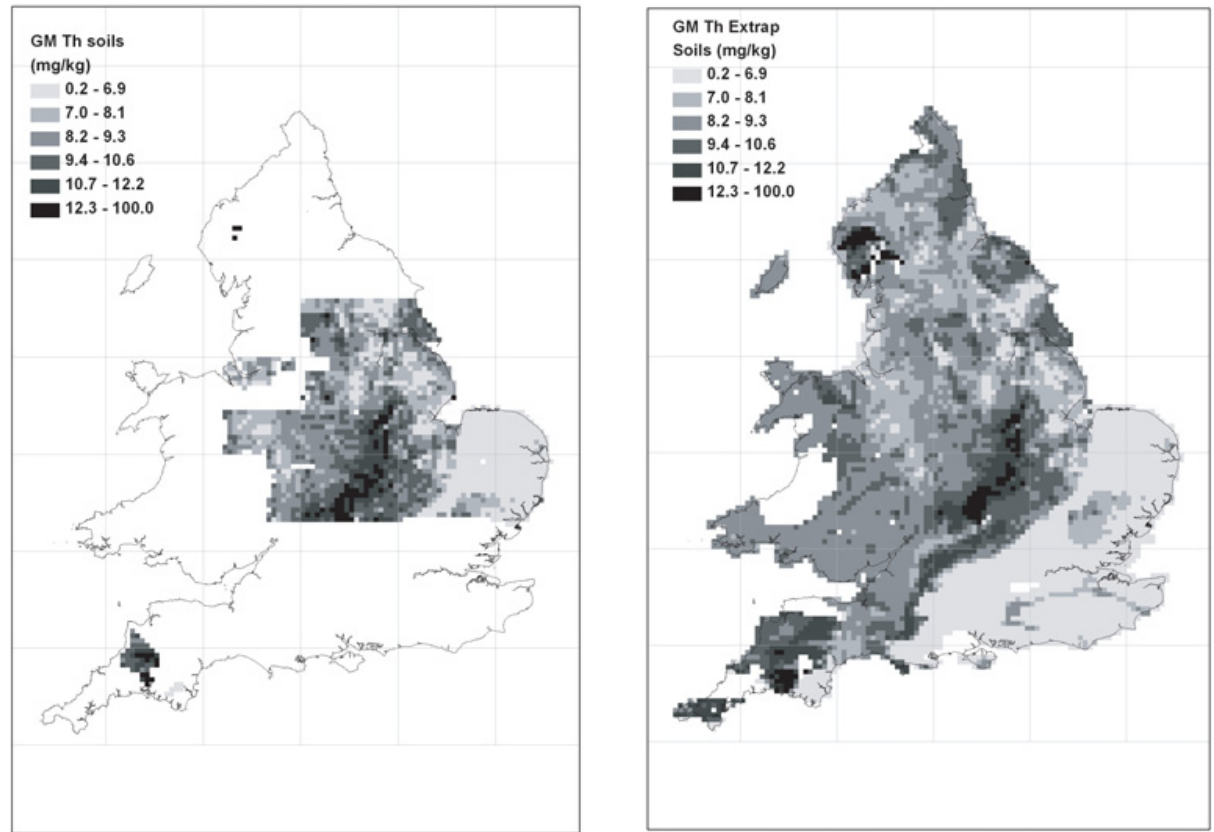

Figure 3. Th in soils $(5 \times 5 \mathrm{~km} \mathrm{GM})$ based on samples (left) and after geological extrapolation (right).

of those products by the total area of the $25 \mathrm{~km}^{2}$ grid square:

$$
\sum_{1}^{n} \frac{\left(\bar{X} 1 \text { Area }_{1}\right)+\left(\bar{X} 2 \text { Area }_{2}\right)+\ldots\left(\bar{X} n \text { Area }_{n}\right)}{25 \mathrm{~km}^{2}}
$$

Where $\bar{X}$ is the GM for a $1 \mathrm{~km}$ grid square/parent material polygon. 
For soils and sediments, spatial datasets were derived for both the (i) geometric mean concentrations from measured samples on a $5 \times 5 \mathrm{~km}$ square basis where data are available and (ii) the extrapolated surfaces covering all of England and Wales. For waters, only geometric mean concentrations were derived, where data are available, as relationships between radioelements in waters and geology were not considered sufficiently strong to justify extrapolation. This means that the data coverage for waters is much more restricted than that for the solid media (Figure 4).
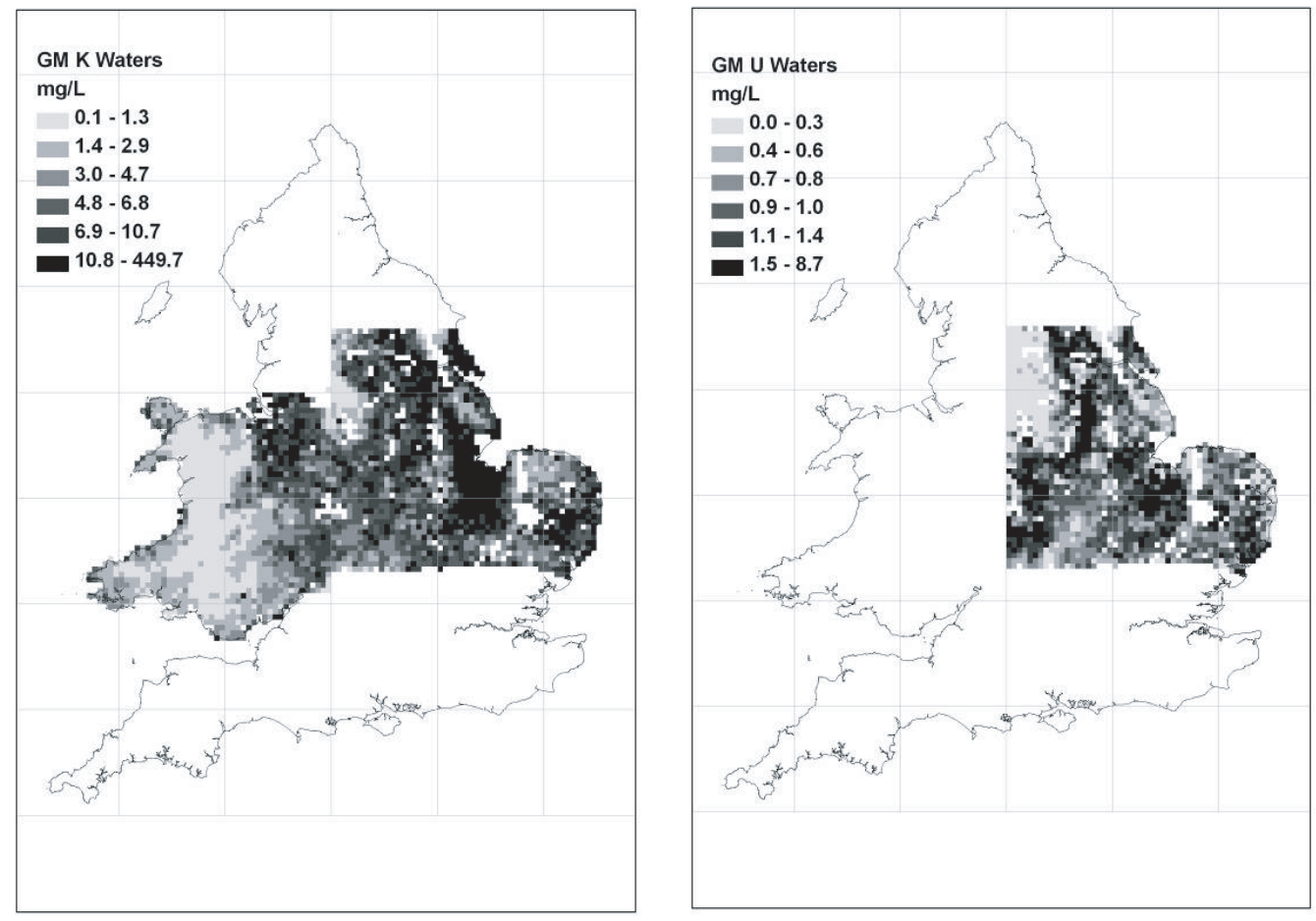

Figure 4. $\mathrm{K}$ and $\mathrm{U}$ in waters $(5 \times 5 \mathrm{~km} \mathrm{GM})$ showing more restricted data coverage.

Specific activities of ${ }^{40} \mathrm{~K},{ }^{232} \mathrm{Th}$ and ${ }^{238} \mathrm{U}$ of $31.6 \mathrm{~Bq} \mathrm{~g}^{-1} \mathrm{~K}, 4.07 \mathrm{~Bq} \mathrm{mg}^{-1} \mathrm{Th}$ and $12.21 \mathrm{~Bq} \mathrm{mg}^{-1} \mathrm{U}$ respectively were used to estimate the activity concentrations of the three radionuclides from the total element concentrations. It was assumed that all ${ }^{232} \mathrm{Th}$ series radionuclides were in approximate equilibrium. In the case of ${ }^{238} \mathrm{U}$ series radionuclides it was assumed that activity concentrations of ${ }^{234} \mathrm{U}$, and the intervening decay products were in secular equilibrium with those of ${ }^{238} \mathrm{U}$; thereafter, assumptions of equilibrium may not be valid because of the different chemical properties and environmental behaviours of the different elements.

\section{APPLICATION OF MEDIA CONCENTRATIONS TO ASSESS DOSE RATES}

External and internal dose rates that have been estimated for selected proposed Reference Animals and Plant (RAP) geometries of the ICRP and for terrestrial biota in the United Kingdom have recently been reported by the authors [8]. External dose rates were estimated using the derived media concentrations and dose conversion coefficients from the ERICA Tool [9].

Internal dose rates were estimated from the results of a literature review and a targeted sampling programme to determine the activity concentration of natural radionuclides found in non-human biota in the United Kingdom. Measured biota concentrations were found to be in good agreement with those 
predicted from environmental media using recommended concentration ratios [5]. This gives confidence both in the derived media concentrations data and the concentration ratios.

Mean total weighted whole-body absorbed dose rates estimated for the selected terrestrial organisms were in the range $6.9 \times 10^{-2}$ to $6.1 \times 10^{-1} \mu \mathrm{Gy} \mathrm{h}^{-1}$. Potassium-40 was the main contributor to both internal and external dose rates.

The water and sediment concentrations together with a literature review, analyses of target fish samples and the ERICA Tool have been used to estimate dose rates to freshwater fish assuming the ICRPs Trout RAP geometry. The radionuclides included in the dose rate estimates were those for which water and sediment concentrations could be derived (e.g. no calculations were made for ${ }^{210} \mathrm{Po}$ and ${ }^{210} \mathrm{~Pb}$ ). Estimated dose rates for freshwater fish were dominated by internal dose received from ${ }^{40} \mathrm{~K}$ with a mean predicted dose rate of $8 \times 10^{-2} \mu \mathrm{Gy} \mathrm{h}^{-1}$. Internal dose rates as a consequence of other radionuclides for which it was possible to estimate expose were of the order $10^{-5} \mu \mathrm{Gy} \mathrm{h}^{-1}$; the maximum contributor to external exposure was again ${ }^{40} \mathrm{~K}$ with a mean predicted dose rate of $2 \times 10^{-5} \mu \mathrm{Gy} \mathrm{h}^{-1}$.

\section{CONCLUSIONS}

The exploitation of the G-BASE dataset described here gave a unique opportunity to derive an extensive media concentration data set for England and Wales. The datasets of natural radionuclide concentrations in biota and media will enable significantly improved assessments of the background exposure of nonhuman species within England and Wales. The media concentration datasets derived here, together with concentration ratios, could be used to derive background exposure values for animals and plants where measurements are lacking.

More complete datasets will be available for environmental media in the future as the G-BASE programme continues. This would allow extrapolated data to be replaced by results from actual samples. Some other, more limited datasets, such as air kerma measurements and soil data for tide washed pastures, were used in the study [5]. Other datasets, such as airborne gamma spectrometry, could also be incorporated if more widespread coverage becomes available.

\section{Acknowledgments}

Wolfson Geochemical Atlas data was used under licence from Imperial College of Science and Technology.

\section{References}

[1] Copplestone D.A., Bielby S., Jones S. R., Patton D., Daniel P. and Gize I. Impact assessment of ionising radiation on wildlife R\&D Publication 128 (Bristol: Environment Agency, 2001).

[2] Copplestone, D., Wood, M.D., Bielby, S., Jones, S.R., Vives, J. and Beresford, N.A. Habitat regulations for Stage 3 assessments: radioactive substances authorisations. October 2003. R \& D Technical Report P3-101/SP1a (Bristol: Environment Agency, 2003).

[3] Johnson C.C. and Breward N., G-BASE: Geochemical Baseline Survey of the Environment. BGS Report CR/04/016 (British Geological Survey, Keyworth, 2004).

[4] Johnson C.C., Breward N., Ander E.L. and Ault L., 2005. Geochem.: Explor-Environ.-Anal., 5 (2005) 347-357.

[5] Beresford, N.A., Appleton, J.D., Barnett, C.L., Bescoby, M.W., Breward, N., Jones, D.G., MacKenzie, A.C., Scheib, C., Wood, M.D. and Thørring, H., Assessment of naturally occurring radionuclides around England and Wales. Project SC030283. (Environment Agency, Bristol, 2007) Available from: http://www.ceh.ac.uk/protect/pages/documents/Assessmnentofnaturallyoccurring radionuclidesinEnglandandWales.pdf.

[6] Webb J.S., Thornton I., Thompson M., Howarth R.J. and L.P. Wolfson, Geochemical Atlas of England and Wales. (Clarendon Press, Oxford, 1978). 
[7] Appleton J.D., Simplified geological classification for radon potential mapping in England and Wales (based on DiGMapGB-50 V3.12). Internal Report IR/05/153R. (British Geological Survey, Keyworth, 2005).

[8] Beresford, N.A., Barnett, C.L., Jones, D.G., Wood, M.D., Appleton, J. and Breward, N., J. Environ. Radioact. 2008 Available on-line: http://dx.doi.org/10.1016/j.jenvrad.2008.03.003

[9] Brown, J.E., Alfonso, B., Avila, R., Beresford, N.A., Copplestone, D., Pröhl, G., Ulanovsky. A. J. Environ. Radioact. 2008 Available on-line: http://dx.doi.org/10.1016/j.jenvrad.2008.03.003. 